\title{
Doctora María Laura Ester Rodríguez Dulanto: en pos de un sueño contra todo y contra todos
}

\section{Doctor Maria Laura Ester Rodriguez Dulanto: in pursuit of a dream against all odds}

Correspondencia Ricardo Iván Álvarez Carrasco ralvarezcarrasco@yahoo.com

Recibido: $10 / 04 / 2019$

Arbitrado por pares

Aprobado: 29/05/2019

Citar como: Álvarez-Carrasco RI. Doctora María Laura Ester Rodríguez Dulanto: en pos de un sueño contra todo y contra todos. Acta Med Peru. 2019;36(2):170-8

\author{
Ricardo I. Álvarez-Carrasco 1,2ab \\ 1 Instituto Nacional Materno Perinatal. Lima, Perú. \\ 2 Asociación de Historia de la Medicina Peruana. Lima, Perú. \\ a Médico cirujano; b especialista en Patología clínica
}

\section{RESUMEN}

La doctora María Laura Ester Rodríguez Dulanto es una de nuestras más admirables figuras médicas, quien poseyó un talento y constancia admirables que fueron capaces de romper con los paradigmas culturales imperantes en la sociedad peruana de los años posteriores a la Guerra del Pacífico; sin embargo, hasta el día de hoy no ha recibido el reconocimiento que ampliamente se merece. El objeto de este artículo es dar a conocer a la comunidad peruana en general y a la orden médica en particular, la vida y obra de esta mujer extraordinaria dentro del contexto histórico en el que se empeñó e hizo realidad, contra todo y contra todos, su más anhelado sueño: convertirse en la primera mujer que se tituló de médico en el Perú.

Palabras clave: María Laura Ester Rodríguez Dulanto; Perú, Historia de la Medicina (fuente: DeCS BIREME).

\begin{abstract}
Doctor Maria Laura Ester Rodriguez-Dulanto is one of our most respectable physicians. She possessed admirable talent and perseverance which were able to break the prevailing cultural paradigms in Peruvian society in the years after the Pacific War; however, to this day she has not received the recognition she deserves. The purpose of this paper is to inform Peruvian community in general and Peruvian physicians, about the life and work of this extraordinary woman within the historical context in which she lived, making her dream come true. Against all odds, she achieved her most longed for dream: become the first woman who qualified as a physician in Peru.
\end{abstract}

Keywords: María Laura Ester Rodríguez Dulanto; Peru, History of Medicine (source: MeSH NLM). 


\section{INTRODUCCIÓN}

La vida y obra de la doctora María Laura Ester Rodríguez Dulanto no solo es la de una mujer académicamente brillante sino la historia de un ser humano que se sobrepuso a un entorno social absolutamente adverso en el que las mujeres tenían un rol secundario, y eso explica por qué sus contemporáneos, en particular sus colegas, no apreciaron la extraordinaria lección de vida que legó a los peruanos de todas las generaciones.

\section{La mujer y su antigua relación con la medicina}

En las sociedades o agrupaciones humanas, desde tiempos remotos, por lo general la mujer ocupó un lugar secundario en la mayoría de las actividades ${ }^{[1]}$. Una de las tareas asignadas a ella fue la preparación de los alimentos, lo que posibilitó la transición a la elaboración de pócimas y emplastos; prácticas que permitieron alcanzar conocimientos acerca del efecto benéfico de las hierbas empleadas en el alivio de los males y padecimientos y también sobre el efecto nocivo de algunas de ellas. Así, la mujer estuvo ligada al origen de la curandería, más tarde convertida en brujería ${ }^{[1]}$.

En relación al campo médico, la actividad por excelencia desarrollada por la mujer fue el arte de partear; muchas de estas parteras también cultivaron la curandería, por lo que prácticamente no hubo sociedad antigua que no contara con alguna de ellas, según su necesidad ${ }^{[1]}$. La mujer no solo tuvo una participación activa en la concepción empírica de la medicina sino también cuando esta se transformó en un ritual mágico-religioso. En este último caso, por un lado, existió la sacerdotisa curandera y por otro la imagen femenina como diosa que motivó su culto por las cualidades sanadoras que se le atribuían ${ }^{[1]}$.

\section{Los estudios médicos femeninos en el mundo y la América Latina}

En 1847, la inglesa Elizabeth Blackwell fue la primera mujer en el mundo que hizo estudios médicos escolarizados, los cuales realizó en la Escuela de Medicina de la Universidad de Ginebra en Estados Unidos, donde completó las 32 semanas académicas exigidas ${ }^{[2]}$ y se graduó en 1849 con las mejores notas de su promoción, sobreponiéndose al ridículo y el ostracismo social de los que fue víctima al principio ${ }^{[3]}$.

La primera médica europea fue la londinense Elizabeth Garrett Anderson, quien fue inspirada por Elizabeth Blackwell, a quien conoció durante una de sus conferencias en Inglaterra; logró titularse en $1865^{[2]}$. Curiosamente el Imperio alemán se resistió tozudamente a admitir mujeres en sus facultades de medicina hasta que, el 20 de abril de 1899, el Káiser Guillermo II firmó el dispositivo que permitía a las féminas optar la licenciatura en medicina y ejercer públicamente; no obstante, antes de eso hubo tres damas que se graduaron en Berlín pero que no ejercieron ${ }^{[4]}$.

La primera médica que ejerció en el África (Sudáfrica) fue la escocesa Jane Elizabeth Waterston luego de graduarse en 1880 en la London School of Medicine for Women ${ }^{[5]}$. Dos años después tocó el turno de la primera asiática, Ogino Ginko, dama japonesa quien al ser contagiada de gonorrea por su esposo se divorció y sintió la humillación de ser atendida por galenos varones, por lo que decidió estudiar medicina para ayudar a otras mujeres; así en 1882 logró su objetivo en la Escuela Normal de Mujeres de Tokio -ahora Universidad de Ochanomizu-, academia privada cuyo cuerpo estudiantil estaba compuesto solo por hombres ${ }^{[6]}$. En 1888 se graduó la primera médica oceánica, se trató de la australiana Constance Stone quien obtuvo el título en el Women's Medical College de Pensilvania y luego el grado de doctora en la University of Trinity College de Toronto, Canadá [7].

En el siglo XVIII, en América Latina, Juana Bartola de Mier Vargas Gutiérrez de la Rozuela fue nombrada protomédica del virreinato de Nueva Granada; a falta de una escuela de medicina local, recibió la enseñanza bajo la tutoría de los frailes médicos del Hospital San Juan de Dios de Mompox ${ }^{[3]}$. No obstante, Ana Galvis Hotz, doctorada en 1877 en la Universidad de Berna - Suiza, es considerada la primera médica no sólo de Colombia sino de Hispanoamérica ${ }^{[3]}$.

En Brasil, en 1875, María Augusta Generoso Estrella viajó a estudiar medicina en Estados Unidos cuando apenas frisaba los quince años ${ }^{[8]}$; cuatro años después, hizo lo propio Josefa Agueda de Oliveira ${ }^{[8,9]}$. Sin embargo, la primera brasilera que se graduó en su propio país fue Rita Lobato Velho López, en $1887^{[1]}$, en la Facultad de Medicina de Bahía ${ }^{[10]}$.

En 1886, Eloísa Díaz Insunza fue la primera chilena que obtuvo el título de médico cirujano en la Universidad de Chile, cuyo diploma le fue entregado, en enero del año siguiente, por el propio presidente de la nación, José Manuel Balmaceda ${ }^{[11]}$. En 1887, hizo lo propio la mexicana Matilde Petra Montoya Lafragua, quien cursó estudios en la Escuela Nacional de Medicina de México ${ }^{[12,13]}$.

En 1889 se graduó la primera argentina, Cecilia Grierson ${ }^{[1,14,15]}$, quien estudió en la Universidad de Buenos Aires ${ }^{[15]}$. Ese mismo año lo hizo en Cuba, la joven Laura Martínez de Carbajal y del Camino ${ }^{[1]}$, quien apenas contaba con 19 años cuando se licenció en medicina y cirugía en la Universidad de La Habana ${ }^{[16]}$. En 1908 se graduó en Montevideo, Paulina Liusi como la primera médica uruguaya ${ }^{[1,17]}$.

En 1921, la dama lojana Matilde Hidalgo Navarro se graduó en la Universidad Central del Ecuador, siendo la primera médica de aquel país, y quien fue también la primera ecuatoriana en ejercer el derecho de sufragio en $1929^{[18]}$. En 1934 Lidia Gertrudis Sogandares Beluche, obtuvo con altos honores el doctorado en medicina en la Universidad de Arkansas, convirtiéndose en la primera médica panameña.

En 1936 se graduó la primera médica en Venezuela, fue la ucraniana Lya Imber Barú en la Facultad de Ciencias Médicas de la Universidad Central de Venezuela (Caracas) ${ }^{[19]}$. En 1947, la médica checa Theresa Cori Gerty, sería la primera mujer que 
recibió el Premio Nobel de Fisiología y Medicina, gracias a sus estudios sobre el metabolismo de los carbohidratos ${ }^{[3]}$.

\section{La mujer y su acceso a los estudios en el Perú}

En el Perú, durante la época colonial, la mujer en general estuvo reservada para el espacio doméstico o religioso. Se le consideraba un ser frágil que debía ser alejado del mundo para no corromper su pureza, siendo protegida por el hombre, ya sea el padre, el esposo o los hijos. La educación, que recibían fundamentalmente las féminas de las élites sociales, las conducía a formarse como esposas y madres; los conocimientos académicos estaban fuera de su alcance ${ }^{[20]}$.

La difusión del pensamiento ilustrado hizo que la concepción de la instrucción femenina empezara a cambiar, creando conciencia sobre la necesidad de instruir a las mujeres más allá de las tareas manuales y la doctrina cristiana, con el propósito que educaran debidamente a los hijos dentro del hogar, aunque siempre manteniendo una prudente distancia del conocimiento científico ${ }^{[20]}$. Empero, ese reconocimiento no cuestionó la función social femenina en el ámbito familiar y doméstico pues, para los ilustrados, las mujeres eran seres de la pasión e imaginación, y no de la razón; de ahí que insistieran en el carácter práctico de su educación ${ }^{[21]}$.

Luego de la independencia, el Estado peruano planteó la incorporación de los sectores excluidos de la ciudadanía y la educación se convirtió en un instrumento idóneo para tal propósito ${ }^{[20]}$. Así, el 6 de octubre de 1825, el Consejo de Estado mandó a establecer un Gineceo, es decir una escuela para niñas, en el convento de la Concepción de Lima, “... donde debía enseñarse Religión, Aritmética, Geografía y labores propias del sexo" [22]. En 1836 se creó la Escuela Normal de Mujeres en el convento de Santa Teresa de Lima, y luego se establecieron escuelas primarias femeninas y colegios nacionales gratuitos para mujeres en cada provincia del país ${ }^{[20]}$. A pesar de la incipiente aceptación del derecho a la instrucción de las mujeres, aún predominaba la idea que los conocimientos académicos e intelectuales las conducirían a desdeñar las cualidades inherentes a su sexo y las convertirían en hombres ${ }^{[20]}$.

En aquella época surgió la figura de la cusqueña Trinidad María Enríquez quien, luego de varios meses de gestiones, consiguió que se emitiera la resolución suprema del 3 de octubre de 1874 que la autorizaba a matricularse en la Universidad del Cusco ${ }^{[20,23]}$, convirtiéndose en la primera peruana en realizar estudios universitarios. Al concluirlos, tres años después, recurrió al Congreso para tramitar su grado académico, gestión que quedó suspendida por el inicio de la Guerra del Pacífico (1879-1883) y se reinició en 1886, cuando el Congreso derivó su pedido a la Corte Superior de Lima, instancia que finalmente le negó el bachillerato ${ }^{[20]}$.

Esta mujer no sólo merece nuestro recuerdo por su pertinaz lucha en el claustro cusqueño, también por ser una de las fundadoras de la Sociedad de Artesanos del Cusco, en $1871^{\text {[24]; }}$ y establecer en su ciudad natal, en 1872, el Colegio Particular de Instrucción Elemental y Media para mujeres ${ }^{[24,25]}$, una de las primeras instituciones de instrucción secundaria femenina en el país; y publicar el semanario La Voz del Pueblo ${ }^{[24]}$. Por realizar estas actividades "vedadas" fue bautizada con el sobrenombre de Don Valentín ${ }^{[24]}$.

Desde la hazañosa gesta de Trinidad Enríquez hasta 1908 solo tuvieron matrícula universitaria algo más de una decena de mujeres peruanas, ya sea para seguir carreras universitarias o como alumnas libres, todas ellas en la Universidad Mayor de San Marcos ${ }^{[20]}$. La inseguridad de obtener los grados universitarios constituyó un gran desincentivo, el cual se reflejó en la ausencia de mujeres en las facultades de Jurisprudencia de las universidades peruanas hasta 1913, cuando Rosa Dominga Pérez Liendo ingresó a la Universidad Mayor de San Marcos ${ }^{[20,23]}$.

En 1888, Margarita Práxedes Muñoz fue la primera mujer que ingresó a San Marcos, a la Facultad de Ciencias, y a fines del siguiente año se graduó con la tesis titulada "Unidad de la materia o identidad sustancial de los reinos inorgánico y orgánico", convirtiéndose en la primera fémina en obtener el grado de bachiller en el Perú ${ }^{[20,23]}$.

Alicia Itati Palermo sostiene que Margarita Práxedes Muñoz ingresó posteriormente en la Facultad de Jurisprudencia de la misma universidad, pero debió dejar los estudios por las dificultades que tenían las mujeres para cursarlos en el Perú, decidiendo entonces estudiar medicina en Chile, amparada por el decreto de 1877 que reconocía la igualdad de hombres y mujeres para el ingreso a la universidad, y en donde obtuvo el título de médica en 1895, siendo una de las cinco mujeres que ejerció esta profesión en la Argentina, durante el siglo XIX ${ }^{[26]}$. Si este aserto tuviera fundamento habría que rescribir una parte de la historia médica peruana.

\section{María Laura Ester Rodríguez Dulanto: su nacimiento y los primeros años}

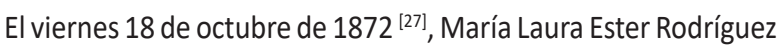
Dulanto vino al mundo en la idílica villa de Supe, situada en la antigua provincia de Chancay y que hoy pertenece a la de Barranca ${ }^{[28]}$; dicho nacimiento ocurrió en la casa familiar, costumbre muy acendrada por aquella época, que se situaba en la zona de la Campiña Baja ${ }^{[29]}$.

Fue bautizada en la parroquia de Santa María Magdalena, anexa a la de San Ildefonso de Barranca, y su partida rezaba: "María Laura Ester, bautizada el 28 de octubre de 1872, de diez días de nacida, en la capilla de Santa María Magdalena de Supe, hija legítima de don Marcelo Rodríguez y de doña María Cristina Dulanto; fueron sus padrinos José Cte. Serva y Da. Tomasa Bustamante" [27].

La recién nacida llegó en uno de los tantos momentos políticamente convulsos de nuestro país. Eran los días en que el gobierno de José Balta utilizaba todas sus influencias para evitar el triunfo de Manuel Pardo Lavalle, líder y fundador del 
Partido Civil, en las elecciones presidenciales; no obstante, muy cerca a los comicios, el mandatario dio marcha atrás, lo que provocó su derrocamiento y muerte a manos del coronel Tomás Gutiérrez, quien era ministro de Guerra. Ello a su vez incitó a la contrarrevolución ciudadana que ultimó al golpista y sus hermanos; todo concluyó con la proclamación congresal de Pardo como presidente de la República el 31 de julio de $1872^{\text {[30] }}$ y se convirtió en nuestro primer gobernante civil, casi tres meses antes del nacimiento de nuestra biografiada.

Su familia materna tuvo al menos dos facultativos entre sus miembros. Su abuelo era el afamado médico Martín Dulanto Silva ${ }^{[31]}$, supano como su nieta, maestro de larga data en el claustro Sanfernandino donde ocupó el cargo de subdecano ${ }^{[31-33]}$ y fue conocido por su avaricia en las calificaciones, ufanándose que jamás había dado un veinte ${ }^{[33]}$; además ejerció como ministro de Instrucción Pública ${ }^{[31,33]}$, entre varios cargos que le fueron confiados. El otro era su tío Genaro Martín Dulanto Núñez, hijo del anterior, quien se recibiría en San Fernando, el año de $1890^{[33,34]}$.

Parte de la infancia de Laura, nombre con el que se le llamaba familiarmente, trascurrió en su tierra natal ${ }^{[27]}$, y se supone, aunque no existe evidencia documental, que allí le enseñaron sus primeras letras, probablemente en la misma casa familiar. Casillas refiere que "... dio muestras de inteligencia y avidez por el estudio desde sus primeros años" [35].

Cuando la pequeña tenía algo más de seis años, estalló la Guerra del Pacífico, conflicto declarado por Chile el 5 de abril de 1879 y que perduró formalmente hasta octubre de 1883 con la firma del Tratado de Ancón. No tenemos una idea cabal sobre el impacto que causó en el espíritu de Laura, el martirologio de Daniel Alcides Carrión, ocurrido el 5 de octubre de 1885 , cuando ella estaba a pocos días de cumplir trece años de edad.

En el verano de 1891 se produjeron lluvias torrenciales, parte de un mega Fenómeno del Niño, que afectaron nuestra costa norte. El 7 de marzo de aquel año el diario El Comercio de Lima informaba sobre una gran inundación ocurrida en Supe la noche del 24 de febrero, señalando que "La población quedó sin techo a causa de una lluvia torrencial de varias horas", luego el 16 de marzo se produjo otra inundación por el desborde del río Seco ${ }^{[36]}$, y el 21 un terrible aluvión que arrasó con el cementerio, plaza, calles, casas, árboles y todo cuanto se encontró en su camino ${ }^{[28]}$.

Estas calamidades hicieron que las autoridades de Supe remitieran diversos elementos materiales, entre ellos los libros de registros de bautizos, a los cercanos poblados de Pativilca, Barranca y Supe Puerto ${ }^{[27]}$; eso explica por qué fue dificultoso el hallazgo de la partida bautismal de Laura y que varios de sus biógrafos dieran fechas equivocadas respecto a su nacimiento, desde la primera semblanza conocida, que se publicó en $1903^{[37]}$, hasta las que se editaron posteriormente, incluidas algunas en el siglo XXI ${ }^{[1,32,38-44]}$.

\section{La instrucción escolar}

Sus padres se trasladaron a la cercana ciudad de Lima donde estudió en la escuela de la señorita Badani, allí obtuvo el título de preceptora de tercer grado ${ }^{[37,43]}$ que era el grado máximo de instrucción al que podía aspirar una peruana ya que no existían colegios secundarios femeninos ${ }^{[23,29]}$. El jurado examinador la honró con un voto extraordinario de felicitación ${ }^{[37]}$; según Elvira García y García “... fue unánime el vaticinio que en esos momentos se hizo, de que esa niña llegaría muy lejos, tanto como el medio se lo permitiera, pues ante las manifestaciones de su poco común talento y la certeza con que absolvía las preguntas, pensaron todos los oyentes que se trataba de un caso especial" [23].

La escuela de la señorita Badani se había fundado el 1 de marzo de 1867, por obra de Magdalena Badani, convirtiéndose en uno de los planteles más prestigiosos de la ciudad, especializándose en la formación de maestras que luego irían a trabajar en diversos lugares del país, coadyuvando a cimentar lo que en el futuro sería la instrucción secundaria para las mujeres ${ }^{[23]}$.

Es en aquel momento que se hizo definitivamente evidente el extraordinario talento, carácter y constancia de Laura. La carencia de un colegio secundario, obstáculo aparentemente insalvable, se convirtió por el contrario en un poderoso estímulo para aspirar a lo impensado ${ }^{[29]}$, a pesar que el contexto social era mayoritariamente contrario a que las mujeres cursaran estudios más allá de los elementales.

Con el apoyo entusiasta de su abuelo materno, y luego del resto de la familia, se hizo repetir las clases que recibía su hermano Abraham Moisés en el Colegio Nacional de Nuestra Señora de Guadalupe ${ }^{[37]}$. Ello le permitió presentarse a los exámenes anuales que tomaban los jurados especiales designados por el Consejo Superior de Instrucción Pública, instancia máxima que asesoraba al ministro del ramo ${ }^{[45]}$, y que aprobó brillantemente hasta concluir la instrucción secundaria ${ }^{[32]}$.

\section{Ingreso a la Facultad de Ciencias de la Universidad Mayor de San Marcos}

El siguiente paso en este largo y ambicioso camino académico ocurriría en mayo de $1892^{[27]}$ cuando rindió el examen general en la Universidad Mayor de San Marcos, obteniendo una nota sobresaliente ${ }^{[37]}$ en virtud de la cual pudo matricularse en la Facultad de Ciencias ${ }^{[29]}$. De esta manera se convirtió en la segunda mujer que logró estudiar en la universidad decana de América, y la tercera en hacerlo en una universidad peruana ${ }^{[20]}$, cuando apenas tenía 19 años de edad [27].

En 1893 alcanzó el grado de bachiller en la sección de Ciencias Naturales de dicha Facultad ${ }^{[37]}$, y cinco años después, el 27 de octubre de $1898^{[43]}$, se le confirió el doctorado al sustentar exitosamente la tesis "Estudios geológicos de la provincia de Chancay", que por acuerdo de la junta de catedráticos se publicó en el Tomo XXVI de los Anales Universitarios ${ }^{[32,37,43]}$. Ello la convirtió en la primera peruana en alcanzar el grado académico de doctor ${ }^{[1]}$. 
Es admitida en San Fernando, donde se titula de médica cirujana

En 1894 llegó al pináculo de sus aspiraciones científicas cuando se matriculó en la Facultad de Medicina de San Fernando, quedando registrada en la página 109 del Quinto Libro de Matrículas, su expediente era el número $38{ }^{[27]}$. Así, su nombre quedó eternamente ligado a la historia grande de nuestra medicina y de los anales sanfernandinos como la primera fémina que inició estos estudios en el Perú ${ }^{[20]}$.

Desde un principio estuvo sometida a duras pruebas personales que siempre pudo vencer ${ }^{[23]}$, debiéndose adecuar a circunstancias sui generis, como el uso cotidiano del saco y la corbata (Figura $\mathrm{N}^{\circ} 1$ ), prendas entonces impropias para una mujer, con el fin de mimetizarse con sus condiscípulos varones; o cuando cursó la cátedra de anatomía humana, que inicialmente siguió detrás de un biombo sin que se le permitiera participar directamente en la disección de cadáveres, por lo que sus compañeros la comparaban con un ciego que quería reconocer una realidad que no veía; no obstante, al regresar a su casa siempre repasaba todos los detalles con su hermano Abraham Moisés, quien también estudiaba Medicina, como si hubiese participado en esas clases prácticas ${ }^{[46]}$.

Su rendimiento sobresaliente obligó al decano Leonardo Villar a autorizar que hiciera las disecciones anatómicas en una sala especial, que compartiría con su hermano ${ }^{[37]}$. En lo que no hubo excepción alguna fue en la exigencia académica de sus maestros, que fue idéntica a la de sus pares masculinos ${ }^{[29]}$.

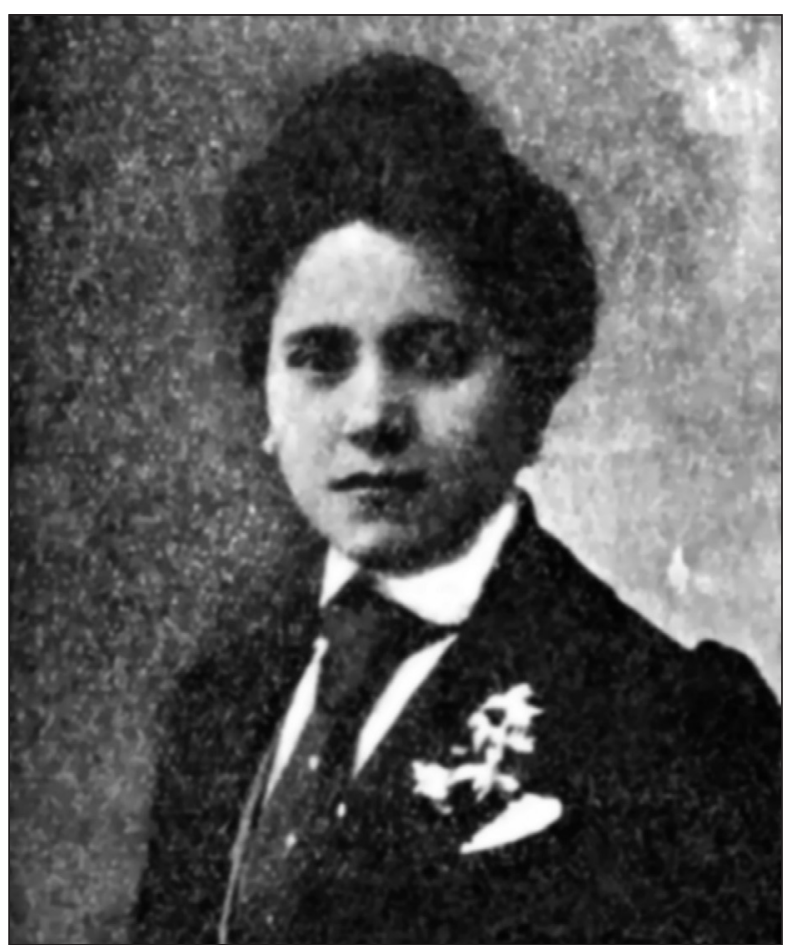

Figura 1. Doctora Rodríguez Dulanto vestida de saco y corbata, tal como acostumbró desde su vida estudiantil en la Universidad Mayor de San Marcos.
Abraham Moisés Rodríguez Dulanto, su hermano menor y compañero inseparable, fue fundamental para que ella alcanzara el sueño de hacerse médica; por ello merece algunas líneas biográficas: nació en Supe en 1874, hizo sus estudios secundarios en el Colegio de Nuestra Señora de Guadalupe ${ }^{[4]}$ de donde egresó en $1891^{[32]}$, en 1892 ingresó a las Facultades de Ciencias y de Medicina de la Universidad Mayor de San Marcos, el 21 de diciembre de $1899{ }^{[32]}$ obtuvo el bachillerato de medicina con la tesis "Estudios criminológicos" ${ }^{[48]}$ y en 1900 el título de médico cirujano ${ }^{[32,47]}$.

En 1917 fue diputado suplente por la provincia de Bolognesi (Ancash) ${ }^{[47]}$ y en 1919 alcanzó su titularidad. Fue un ferviente partidario de Augusto B. Leguía, que lo designó ministro de Hacienda y Comercio ${ }^{[49]}$ en mayo de $1921{ }^{[47]}$; durante su administración, el 9 de marzo de 1922, se estableció el Banco Central de Reserva ${ }^{[50]}$, y se gestionaron los fondos para la construcción del parque Universitario y la plaza San Martín de Lima. A la caída de Leguía se confinó al ostracismo político hasta el fin de sus días, falleciendo en Lima ${ }^{[32,42]}$ en $1936^{[42]}$.

Las excelentes calificaciones de Laura hicieron que el Congreso Nacional expidiera la Resolución Legislativa del 15 de diciembre de 1895, que la premió con una mesada mensual de 40 soles, para subvencionar sus estudios médicos ${ }^{[27,37,40,43]}$.

Elvira García y García nos legó el relato de un episodio muy poco conocido, que sucedió durante su etapa de estudiante sanfernandina: "Un año tuvo que suspender sus exámenes formales de promoción en la fecha fijada, por haber sido atacada de violenta enfermedad, que hizo abrigar serios temores; pero supo reemplazar el tiempo perdido con la convalecencia a la orilla del mar, con lo que, al mismo tiempo que rescataba sus fuerzas físicas, ganaba en inteligencia y seguía recibiendo las lecciones no escuchadas por su leal hermano, compañero inseparable en toda su vida estudiantil", y luego agregó "El nuevo año la tomó convenientemente preparada rindiendo sus exámenes en los primeros meses, pudiendo matricularse en el año superior inmediato, con lo que igualó sus estudios" [23].

Fue alumna externa e interna en el Hospital de Santa Ana, nosocomio exclusivo para mujeres, pues entonces era inadmisible que atendiera pacientes varones, siendo sus maestros los doctores Néstor Corpancho y Eduardo Bello Porras ${ }^{[39]}$.

En 1898 publicó en La Crónica Médica, órgano oficial de la Sociedad Médica Unión Fernandina y nuestra principal revista galénica por aquellos años, el reporte que tituló "Enorme quiste del ovario acompañado de otro pequeño" ${ }^{[44]}$, en el que detalló la cirugía efectuada por el doctor Corpancho en la sala San Pedro del Hospital de Santa Ana, el 9 de abril de aquel año ${ }^{[51]}$. Este fue el primer artículo médico escrito por una mujer peruana.

No conforme con ello, el 28 de marzo de 1900, aún siendo interna, escribió otro interesante reporte: "Fibromioma uterino - Histerectomía abdominal conformación de pedículo extraperitoneal - Curación", el cual remitió a la misma revista que lo publicó en su número 270 , fechado el 31 de marzo de ese año ${ }^{[52]}$. 
Estaba llegando al final de la carrera sin merecerle favor a nadie. No hubo ninguna recomendación en su favor, menos de su severo abuelo, ni siquiera la aureola que la acompañó desde la Escuela de la señorita Badani y la Facultad de Ciencias de San Marcos le sirvió de pasaporte para culminar sus estudios médicos, ella sola bastaba y así su triunfo fue enteramente meritorio ${ }^{[23]}$.

El 23 de diciembre de 1899 optó el bachillerato en medicina con la tesis "Empleo del ictiol en las inflamaciones pelvianas" [27,53], contenida en 59 folios y que actualmente se halla en la Biblioteca Central Pedro Zulen de la Universidad Nacional Mayor de San Marcos ${ }^{[48]}$.

El 26 de septiembre de 1900 prestó juramento para ejercer la profesión médica, tal como reseñó el diario El Comercio: "La señorita doctora Laura E. Rodríguez Dulanto ha prestado ayer el juramento respectivo para ejercer la profesión de médica y cirujana” [54]; más adelante agregaba: “... El nombre de la señorita doctora Rodríguez Dulanto pertenece hoy a la historia científica del Perú; en ella ha de figurar como la primera persona de su sexo que se ha abierto paso hasta las profesiones liberales y como la primera representante del feminismo, que cada día hace más progresos en las naciones más civilizadas" [54].

El jueves 25 de octubre de 1900, logró el grado de doctora en medicina ${ }^{[27,43]}$. Al respecto, Tauro reiteró que su rendimiento fue brillante, mereciendo los primeros premios, así como las contentas para los grados de bachiller y doctorado ${ }^{[43]}$.

Seguramente la emoción y la alegría desbordaron al doctor Martín Dulanto, su querido abuelo, quien fue testigo de excepción de la plena realización del más caro anhelo de su ilustre nieta. En enero de $1911^{[55]}$, cuando falleció este antiguo y apreciado maestro sanfernandino, Carlos Granda, representante de la Facultad de Ciencias de San Marcos, le dedico las siguientes palabras en el camposanto: "quiso dar al Perú en una de sus descendientes la primera médica diplomada que se registra en los anales de la universidad mayor y lo logró con éxito brillante, formando y educando a su nieta, la distinguida profesional, doctora Laura Rodríguez Dulanto".

La Crónica Médica no hizo una reseña especial sobre aquellos sucesos, pero en su número 285 , fechado el 15 de noviembre de 1900, editó un artículo titulado "Mujeres Médicas", firmado con las iniciales F.V.V., en cuyo último párrafo se decía textualmente: "En el Perú la distinguida señorita Laura Rodríguez obteniendo en todos sus exámenes la nota de sobresaliente y distinguiéndose por su asiduidad a la clínica de enfermedades de señoras; recibida de Doctora en el presente año de 1900, y siendo la primera en el Perú" ${ }^{[4]}$.

\section{Ejercicio profesional}

La misoginia imperante en la sociedad peruana a principios del siglo XX, hizo que la presencia de una médica se tomara como un exotismo, poco menos que un fenómeno anómalo que más bien podía ser un peligroso antecedente para que otras féminas intentaran algo semejante; ello explica el desdén y resistencia, poco disimuladas, que le dispensó la comunidad médica de Lima. Alrededor de su vida profesional se inventaron fábulas, historias y leyendas novedosas, completamente desprovistas de verdad, que caían en camino preparado por la maledicencia y la envidia, y le hicieron mucho daño ${ }^{[23]}$.

Tal situación sólo le permitió ejercer la profesión en la Escuela Normal de Mujeres, el Liceo Fanning, dirigido por la educadora Elvira García y García, y los conventos de la Concepción, Jesús María y Nazarenas ${ }^{[27,42]}$. No pudo laborar en el Hospital de Santa Ana, el único al que podía aspirar por aquellos años. Una vez más esta iniquidad no la arredró, ya desde sus años estudiantiles decidió especializarse en ginecología ${ }^{[23]}$, que era un tópico recurrente entre la mayoría de sus pacientes.

En alguna ocasión, el cirujano francés Félix Larré, médico que residió intermitentemente en nuestra capital ${ }^{[56]}$, se refirió a ella en los siguientes términos: “... Estoy admirado de encontrar en el Perú a una mujer de tanto mérito y de tan singular talento. Si Laura Rodríguez hubiera nacido en Francia, sería mimada, por todas las clases sociales y poseería una gran fortuna" [23]. Ello constituyó una merecida crítica a la sociedad peruana y, en particular, a la comunidad médica.

A pesar de lo mencionado, Laura tuvo una posición moderada dentro del movimiento feminista reinante en la época, que tenía diversos matices; tanto así que no confiaba en el sufragio femenino y en la participación femenina en la vida política ${ }^{[1,57]}$.

En 1910, se reagudizó el antiguo diferendo fronterizo con el Ecuador al trascender informaciones que el laudo del rey de España aceptaría ampliamente las tesis jurídicas del Perú, entonces estallaron violentas manifestaciones en Guayaquil y Quito, y ambos países se colocaron en pie de guerra; durante varias semanas la conflagración parecía probable, pero una oportuna intervención de Argentina, Brasil y Estados Unidos restableció la paz ${ }^{[58]}$.

Durante aquel tiempo de incertidumbre se hizo evidente que carecíamos de un número suficiente de personal de enfermería para atender las contingencias propias de la guerra, y en esa amarga circunstancia la doctora Rodríguez fue una de las fundadoras de la Unión Patriótica de Señoras, que estableció una efímera escuela de enfermería, cuyas clases se dictaron en algunas salas de los hospitales Dos de Mayo y Santa Ana, ambos de Lima (Figura $N^{\circ} 2$ ); allí se enseñó a las voluntarias los procedimientos elementales para socorrer a los soldados heridos

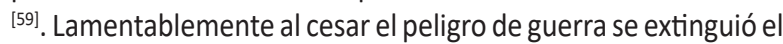
primer intento serio de establecer la enseñanza formal de esta profesión en nuestro país.

En noviembre de 1913 se realizó en Lima el $5^{\circ}$ Congreso Latino Americano y $6^{\circ}$ Panamericano de Medicina ${ }^{[42]}$, eventos de gran resonancia continental por la presencia de facultativos de prácticamente todo el continente y por la gran cantidad y calidad de las investigaciones presentadas. Con ese motivo nuestra biografiada presentó la ponencia titulada "La necesidad de la declaración obligatoria de la Tuberculosis en América y el establecimiento de Sanatorios sostenidos por el Estado para los tuberculosos" ${ }^{[42]}$. 


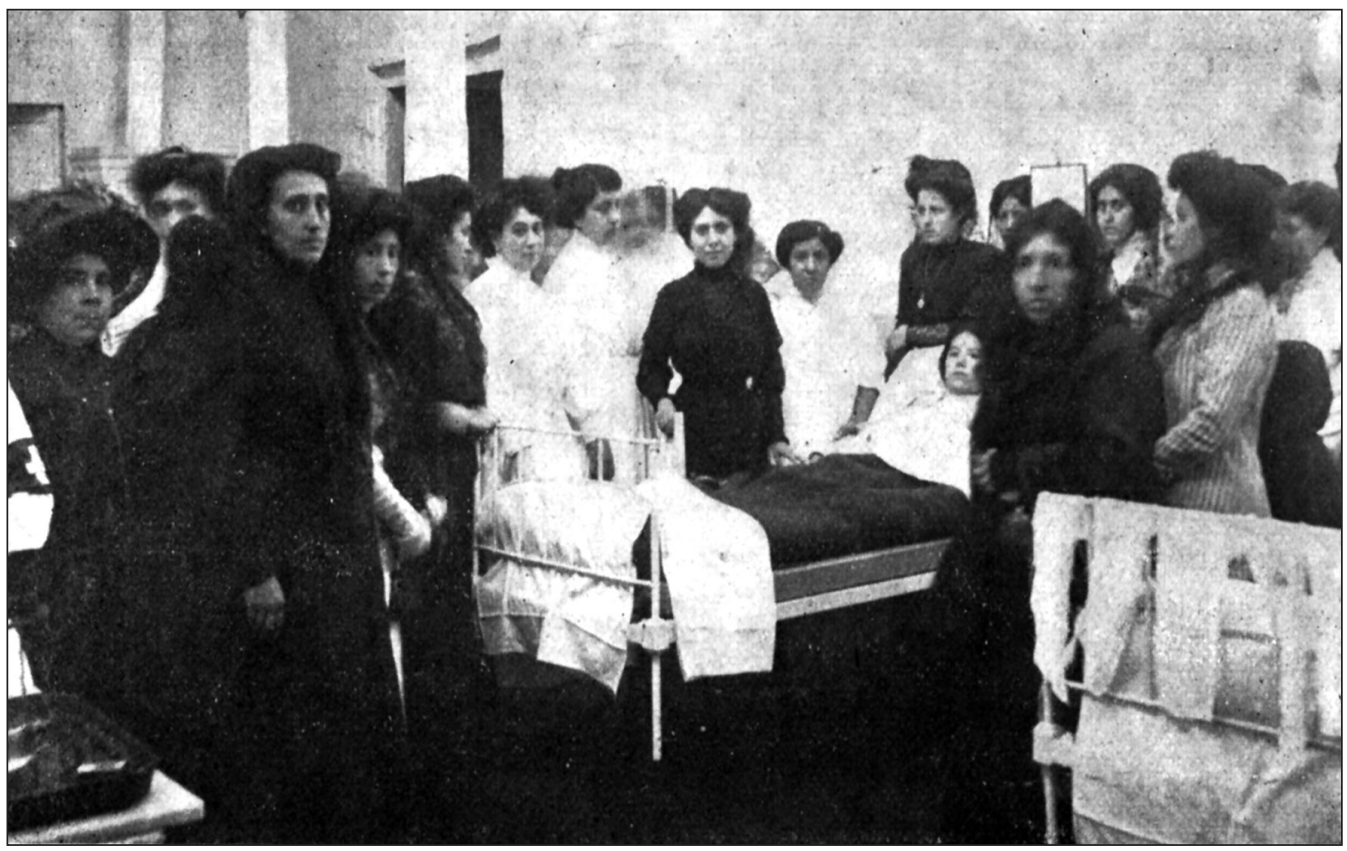

Figura 2. Doctora Rodríguez Dulanto impartiendo clases de enfermería a las integrantes de la Unión Patriótica de Señoras, en el Hospital de Santa Ana, Lima.

\section{El fin de su proficua existencia}

Esta mujer extraordinaria falleció en Lima, el domingo 6 de julio de 1919, a los 46 años de edad, "... después de padecer una prolongada enfermedad" [27], siendo inhumada en el nicho 89-D del pabellón San Marcos en el Cementerio Presbítero Maestro. El destino quiso que su vida y el descanso eterno estuvieran ligados a ese santo evangelista ${ }^{[29]}$. No contrajo matrimonio $\mathrm{ni}$ tuvo hijos ${ }^{[29]}$

Este óbito que debió merecer la atención y el pesar público generalizados pasó más bien inadvertido ya que apenas dos días antes, el viernes 4 de julio de 1919, se había producido el golpe de Estado que derrocó al presidente José Pardo Barreda y entronizó en el poder a Augusto B. Leguía, dando así principio al llamado Oncenio. La Crónica Médica ignoró esta muerte y no hizo ninguna mención en lo que restó de 1919; ello constituye una paradoja ya que por entonces uno de sus redactores era el doctor Eduardo Bello Porras ${ }^{[60]}$, quien había sido, aún joven, su profesor de cirugía en el Hospital de Santa Ana.

En 1928, nueve años después de su muerte, otra peruana, María Mercedes Cisneros Mejía, natural de Sicuani (Cusco) ${ }^{[61]}$, alcanzaría el título de médico cirujano ${ }^{[1]}$, casi tres décadas después que la doctora Rodríguez lo obtuviera brillantemente. Valladares refiere que, en 1892, la señorita Eudocia Pauta ingresó a la Facultad de Ciencias de San Marcos y luego siguió estudios médicos en San Fernando ${ }^{[20]}$; sin embargo, no existe evidencia que alcanzara a titularse. En 1981 se graduó en San Fernando, Licenia Ihuaraqui Canayo, la primera médica originaria de un pueblo indígena selvático, en este caso el Piro, que luego laboró en el Hospital de Apoyo de Yarinacocha ${ }^{[62]}$.

\section{Homenajes póstumos}

Sólo algunos pocos lugares, todos en el departamento de Lima, recuerdan, sin el brillo que realmente merece, la memoria de la doctora Rodríguez Dulanto:

- El busto de bronce que se develó el 12 de enero de $1986^{[63]}$ en el Parque de la Historia de la Medicina Peruana, ubicado frente al Hospital Dos de Mayo de Lima, que originalmente tenía una pequeña lámina que rezaba "Placa recordatoria a la Dra. Laura Esther Rodríguez Dulanto. 1876-1919” [27]. Esta escultura fue robada por la creciente delincuencia citadina, al igual que todos los demás bustos de aquel parque.

- El Centro Materno Infantil que lleva su nombre y se ubica en la calle $30 \mathrm{~N}^{\circ} 150$, en la urbanización El Pinar, distrito de Comas, el cual se fundó el 24 de mayo de 1994.

- El Hospital Materno Infantil de Supe, inaugurado el 13 de agosto de 1971, con la presencia del entonces ministro de salud, general FAP Fernando Miró Quesada Bahamonde ${ }^{[28]}$, y que a partir del 20 de diciembre de 2004 gracias a la Resolución Ministerial N 1232-2004/MINSA, pasó a denominarse Hospital de Supe Laura Esther Rodríguez Dulanto ${ }^{[64]}$. Actualmente depende del gobierno regional de Lima Provincias.

- Una calle del distrito limeño de San Miguel.

El 18 de octubre de 2018, el buscador Google le rindió homenaje dedicándole el doodle de aquel día en recuerdo al 146 aniversario de su nacimiento. Matías Fuentes, gerente de comunicaciones de esta empresa para el Perú y Argentina, dijo "Queremos celebrar, a través de nuestros doodles, la vida de extraordinarias mujeres que marcaron la historia de la humanidad", y luego agregó 
"Hoy homenajeamos a la primera mujer que juró la demanda hipocrática en el Perú, lo que significó un hito sin precedentes para la medicina en el país".

\section{Colofón}

La trascendente vida y obra de la doctora María Laura Ester Rodríguez Dulanto aún aguarda ser reconocida en su genuina magnitud, ella dio el primer paso para lograr la unión participativa de la mujer en la vida nacional, en igualdad de condiciones, contribuyendo eficazmente al bienestar y desarrollo de la salud pública nacional ${ }^{[40]}$.

Irónicamente, hasta donde se ha revisado, ninguna fémina escribió algo relevante sobre la vida y obra de esta ilustre médica, con la sola excepción de Elvira García y García, eminente educadora y militante en el incipiente movimiento feminista de su época ${ }^{[65]}$, quien lo hizo en el ya lejano año de $1925^{[23]}$.

Por lo tanto, es un deber moral ineludible de todos los miembros de la orden médica peruana, y en particular de las mujeres que la conforman, situar en el lugar que le corresponde al recuerdo y la memoria de esta dama de inteligencia, constancia y pundonor singulares, que es orgullo no sólo del Perú, sino de toda la América Latina.

Fuente de financiamiento: autofinanciado.

Declaración de conflictos de interés: el suscrito no tiene ninguna relación, condición o circunstancia que altere la objetividad del contenido de este artículo.

\section{REFERENCIAS BIBLIOGRÁFICAS}

1. Pamo O. Una visión histórica de la participación femenina en la profesión médica. Rev Soc Peru Med Interna. 2007; 20(3):109-22.

2. Roth $\mathrm{N}$. The personalities of two pioneer medical women: Elizabeth Blackwell and Elizabeth Garrett Anderson. Bull. N. Y. Acad. Med. 1971;47(1):67-79.

3. Martínez A. Del masculino pasado al femenino futuro: mujer, historia y medicina. Rev Salud Hist Sanid. 2007;2(3):5-20.

4. F.V.V. Mujeres médicas. La Crónica médica. 1900;17(285):332-4.

5. Van Heyningen E. Jane Elizabeth Waterston-Southern Africa's first woman doctor. J Med Biogr. 1994;(4):208-13.

6. Watanabe JG. La primera doctora. Barcelona: Seix Barral; 2009.p.11-15.

7. Hamer M. Constance Stone and pioneering women of Australian medicine. Yarra, Australia: McMillan Publishers Australia PTY Ltd.; 2016. p.18,19.

8. Marcolin N. Uma longa jornada. Pesquisa Fapesp. 2005; (111):10-1.

9. Guardia S. Historia de las mujeres en América Latina. Segunda edición. Lima: Centro de Estudios la mujer en la historia de América Latina; 2013. p.127.

10. Rita Lobato. J Bras Patol Med Lab. 2003;39(1):3.

11. Jiménez A. Doctora Eloísa Díaz Insunza. Rev Chil Infect. 2000;17(1):76-8.
12. Carrillo A. Matilde Montoya: primera médica mexicana. México: Documentación y Estudios de Mujeres AC (DEMAC); 2002. p.9-13.

13. Rodríguez A, Castañeda G. Inicio de las mujeres en la medicina mexicana. Rev Fac Med (Méx). 2015;(58)2:36-40.

14. Pérgola F. Cecilia Grierson, primera médica argentina. Rev Argent Salud Pública. 2015;6(24):47-8.

15. Zuckerberg C. Cecilia Grierson (1859-1934). Medicina (Buenos Aires). 2005;65(6):1-2

16. Purón E. Presencia de la mujer en la Universidad de La Habana. Nosotras. 2013;4:8-9.

17. La doctora Paulina Luisi. Acción Femenina. 1925;8(51):2-11.

18. Abad E. Visión de género en la formación docente de la carrera plurilingüe de la Facultad de Filosofía, Letras y Ciencias de la Educación [Tesis de maestría]. Quito, Ecuador: Universidad Central del Ecuador; 2014

19. Sánchez D. Anécdotas médicas en la historia de Venezuela. Fundación Empresas Polar. Caracas: Tipografía Arte Tip; 2015. p.157.

20. Valladares 0 . La incursión de las mujeres a los estudios universitarios en el Perú: 1875-1908. CIAN. 2012;15(1):105-23.

21. Rosas C. Educando al bello sexo: la mujer en el discurso ilustrado. En: Scarlett O’Phelan Godoy, editora. El Perú del Siglo XVIII. La Era Borbónica. Lima: Pontificia Universidad Católica del Perú-Instituto Riva-Agüero; 1999. p.349-413

22. C.L.S. Algo para una ley de instrucción o sean apuntaciones sobre los medios de mejorar la instrucción pública del Perú. Lima: Imprenta Liberal de El Correo del Perú; 1874. p.163.

23. García E. La mujer peruana a través de los siglos. Segundo tomo. Lima: Imprenta Americana; 1925.p.393-396,463-465,498$500,504,505,798,799$.

24. Velazco C. Doña Trinidad María Enríquez. Pro Cultura. Revista femenina, Cusco. 1947;1(2):12-6.

25. Examen Público del Colegio Particular de Instrucción Elemental y Media. Directora Trinidad M. Enríquez. Cusco: Imprenta del Heraldo; 1873.

26. Palermo A. Mujeres profesionales que ejercieron en Argentina en el siglo XIX. Convergencia. 2005;(38):59-79.

27. Díaz H. Primera médica peruana, Dra. Laura Esther Rodríguez Dulanto. An Fac Med Lima. 2007:68(2):181-4.

28. Zubieta F. Calendario histórico regional. Barranca - Huaura Huaral. Primera edición. Huacho: Sin pie de imprenta; 1996. p. $43,44,47,105,175$

29. Álvarez R. Colegio Médico del Perú. Una visión retrospectiva de sus primeros 50 años de historia. Lima: REP S.A.C.; 2017.p.41,42.

30. Vargas R. Historia general del Perú. Tomo IX. Segunda edición. Barcelona: Editorial Milla Batres; 1984. p.179-194.

31. Enciclopedia biográfica e histórica del Perú. Siglos XIX-XX. Tomo IV. Primera edición. Bogotá: Editorial Milla Batres; 1994. p.90.

32. Rabí M. Diccionario histórico biográfico médico del Perú. Siglos XVI-XX. Lima: Larchgrafic SAC; 2007. p.220,451,452.

33. Valdizán H. Diccionario de Medicina Peruana. Tomo III. Apéndice de la Revista Anales de la Facultad de Medicina; 1957. p.69,70,78,79.

34. Razón nominal de los médicos con título legal para ejercer su profesión en el Perú. Almanaque de El Comercio para 1895. Año IV. Lima: Imprenta de El Comercio; 1895. p.289. 
35. Casillas W. Laura Rodríguez Dulanto: primera médica cirujana peruana. Rev Peru Pediatr. 2007;60(1):67-8.

36. Rocha A. Los aluviones de 1891 y la iniciación de las investigaciones sobre el fenómeno "El Niño" (ENSO) en el Perú. Lima: Academia Peruana de Ingeniería; [citado: 29 mar 2019]. Disponible en: http:// apiperu.com.pe/wp-content/uploads/presentaciones/articulos-ylibros/meganino_1891.pdf

37. Seoane B, Seoane G. El Biógrafo Americano. Tomo I. Lima: Librería escolar e imprenta E. Moreno; 1903. p.25,26.

38. Alayza F. La mujer y la medicina peruana. Acta Méd Peru. 1991;15(2):70-3.

39. Alva V. Intervención de la mujer en la medicina. En: Salaverry O, Delgado G, editores. Historia de la Medicina Peruana en el Siglo XIX. Tomo II. Lima: Universidad Nacional Mayor de San Marcos; 2000. p.1278-9.

40. Delgado G, Rabí M. Dra. Laura Esther Rodríguez Dulanto (Supe 1875 - Lima 1919). En: Delgado G, Rabí M, editores. Evolución Histórica de la Facultad de Medicina de San Fernando. Universidad Nacional Mayor de San Marcos. Sesquicentenario de la Facultad de Medicina, 1856-2006. Segunda edición. Lima: Universidad Nacional Mayor de San Marcos; 2006. p.121-2.

41. De los Ríos E. Una bella historia: Laura Rodríguez Dulanto. Revista Caretas. 5 de febrero de 1990.p.54-5.

42. Enciclopedia Biográfica e Histórica del Perú. Siglos XIX-XX. Tomo IX. Primera edición. Editorial Milla Batres. Bogotá: Panamericana Formas e Impresos S.A.; 1994. p.27.

43. Tauro A. Diccionario Enciclopédico del Perú. Apéndice. Editorial Mejía Baca. Lima: Editorial Jurídica S.A.; 1975. p.258.

44. Valdizán H. Diccionario de Medicina Peruana. Tomo V. Cuarta parte. Apéndice de la Revista Anales de la Facultad de Medicina; 1959. p.272.

45. Gamarra A. Datos históricos acerca de los establecimientos se Segunda Enseñanza que actualmente funcionan. Lima: Imprenta Torres Aguirre; 1919. p.41.

46. López A. Laura Esther Rodríguez Dulanto, la primera mujer universitaria y cirujana de Perú. El País. Sección Medicina. Madrid, 18 de octubre de 2018

47. Reaño J. Historia del Leguiismo, sus hombres y sus obras. Primera edición. Lima: Edición Ernesto Balarezo P; 1928. p.299.

48. Muñoz M, Valladares O. Catálogo de Tesis de Medicina UNMSM 18571899; 2012 [citado: 1 abr 2019]. Disponible en: historiaglobalonline. com/wp-content/uploads/pdf/01-valladares.pdf.
49. Gálvez J, García E. Historia de la Presidencia del Consejo de Ministros. Tomo I. Lima: Empresa Peruana de Servicios Editoriales S.A.; 2016. p.278.

50. Basadre J. La misión Kemmerer y su importancia para el Banco Central. Banco Central de Reserva del Perú. Moneda. Informe Especial; 2006. p.9,12.

51. Alayza F. Historia de la cirugía en el Perú. Lima: Editorial Monterrico S.A.; 1992. p.257.

52. Rodríguez L. Fibromioma uterino - Histerectomía abdominal conformación de pedículo extra-peritoneal - Curación. La Crónica Médica. 1900;17(270):81-4.

53. Lastres J. Historia de la Medicina Peruana, Volumen III. Universidad Nacional Mayor de San Marcos. Lima: Imprenta Santa María; 1951. p.300.

54. Primera mujer médico. El Comercio. Edición Mañana. Lima, jueves 27 de septiembre de 1900.

55. Necrología. La Crónica Médica. 1911;28(529):14.

56. Valdizán H. Diccionario de Medicina Peruana. Tomo IV. Cuarta parte. Apéndice de la Revista Anales de la Facultad de Medicina; 1958. p.333.

57. Ramos C, Baigorria M. Trinidad María Enríquez. Una abogada en los Andes. Lima: Palestra Editores S.A.C.; 2005. p.85-97,127-8.

58. Bruce R. Las relaciones Ecuador-Perú: una perspectiva histórica. En: Ecuador-Perú. Horizontes de la negociación. Primera edición. Quito: Rispergraf; 1999. p.94.

59. Noble attitude of the women of Perú. Perú to Day. 1910;2(4):13-6.

60. Personal de redacción de La Crónica Médica de 1884 hasta 1933. La Crónica Médica. 1934;51:69.

61. Proaño M. Regiones y personajes del Perú. Lima: Imprenta de la Escuela de la Guardia Civil y Policía; 1936. p.172,173.

62. Unidad Departamental de Salud - Ucayali. Resolución Directoral $\mathrm{N}^{\circ}$ 317-87-DUDSU-DP. Pucallpa, 30 de diciembre de 1987.

63. Delgado G. Un parque con historia. En: Salaverry O, Delgado G, editores. Historia de la Medicina Peruana en el Siglo XIX. Tomo I. Lima: Universidad Nacional Mayor de San Marcos; 2000. p.33.

64. Ministerio de Salud. Resolución Ministerial N 855-2005/MINSA. Lima, 4 de noviembre de 2005.

65. Marrou A. Elvira García y García y la educación peruana. Invest. Educ. 2013;17(2):21-47. 